\title{
Neonatal Outcome in Early and Late Gestational Diabetes Mellitus
}

\author{
Misra S', Das NK²
}

\begin{abstract}
Introduction: Gestational diabetes mellitus in pregnancy is quite common and the prevalence is higher in ethnic communities. This study aims to look at neonatal complications and NICU admissions occurring in early and late onset gestational diabetes for better monitoring and management of neonatal complications. Material and Methods: This is a prospective observational study in a neonatal intensive care unit of a tertiary hospital in Kolkata over a year. Neonates born to mothers with gestational diabetes were admitted for observation in NICU. Their demographics and complications were noted. Maternal details were collected from maternal records. Results: Gestational diabetes was noted in $45.8 \%$ in early pregnancy. $33.3 \%$ mothers were managed with insulin. $75 \%$ delivered by Ceasarean section. Preterm delivery noted in $23.6 \%$.Complication were $60.60 \%$ in early onset gestational diabetes which was significantly greater $(p<0.05)$. Hyperbilirubinaemia and hypoglycaemia were the commonest complication. Macrosomia and congenital complications were seen in early onset GDM. Conclusion: Strict monitoring and intervention is necessary in early gestational diabetes to prevent neonatal complications.
\end{abstract}

Key words: Neonatal complication, Gestation diabetes, Early onset

\section{Introduction}

G estational diabetes is described as diabetes occurring "only during pregnancy, being absent at other times." Though frequency is highly variable prevalence of $4 \%$ is seen in all ethnic population 1 . Compared with white European women the prevalence rate for GDM is increased approximately eleven folds in women from Indian subcontinent ${ }^{2}$. The neonatal complications are preventable as they depend on maternal glycaemic control. Screening for diabetes mellitus is currently being offered to all pregnant women between 24 and 28 weeks With detection of maternal hyperglycaemia and strict management the incidence of macrosomia, congenital anomalies and still birth have reduced though the morbidity persists in an altered and milder pattern. Alarge multi-ethnic cohort study ${ }^{3}$ has shown that despite early testing and intensive intervention early GDM diagnosis in high risk women is still associated with adverse outcome. The management
${ }^{1}$ Dr. Saheli Misra, MBBS, DNB (Pediatrics), Associate Professor, ORCID ID; http://orcid. org/0000-0003-4449-7453, ${ }^{2}$ Dr. Niloy Kumar Das, MBBS, MD, Assistant Professor, Both from the Department of Paediatrics, Employees' State insurance Corporation Postgraduate Institute of Medical Science and Research (ESIC PGIMSR) \& ESIC Medical College, Joka, India.

\section{Address for correspondence}

Dr. Saheli Misra, Associate Professor, Flat 3,Narmada,175/W/1 Maniktala Mn Road Kolkata 54, India.

Tel No; +919831180085

E-mail: saheli2069@gmail.com

Acknowledgements: We would like to thank Dr. Jayasri Mitra, Dean, ESIC PGIMSR and Medical College, Joka, Dr. Joydeb Roy choudhury, HoD, and Dr. Nalini Arora, Professor, Obstetrics and Gynaecology Department and all residents and postgraduate trainees of O\&G and Pediatrics department for their cooperation.

Funding: Nil

Conflict of Interest: None

Permission from IRB: Yes

\section{How to cite}

Misra S, Das NK. Neonatal Outcome in Early and Late Gestational Diabetes Mellitus. J Nepal Paediatr Soc 2017;37(1):41-44.

doi:http://dx.doi.org/10.3126/jnps.v37i1.16426

This work is licensed under a Creative Commons Attribution 3.0 License. 
of such newborns is a challenge for paediatricians in neonatal care. In our study we attempted to look at the pattern of neonatal complication in babies of gestational diabetics in our hospital. Since there were early onset gestational diabetics, we compared the complication in early onset gestation diabetes with late onset gestational diabetes.

\section{Material and Methods}

This study was carried out at the neonatal intensive care unit of our hospital over a period of one year from April 2015 to March 2016. All mothers with gestational diabetes were considered as high risk pregnancies whose babies were admitted to NICU following delivery. Informed consent was taken from mothers and clearance was taken from institutional committee. All neonates were observed for congenital anomalies at birth and at 24 hours. They were observed for 24 hours and transferred to mothers in postnatal wards provided there were no complications. The blood sugar was routinely estimated using dextrostix at 2,6,12 and 24 hours $^{4}$ for all babies. The newborns were also monitored for respiratory distress, hypocalcaemia, and polycythaemia. A base line calcium level was done in all cases. Echocardiography was done in cases with clinical finding. Those with jaundice had bilirubin assessed and underwent phototherapy if their serum bilirubin was in the phototherapy range.

All new-borns were monitored in the postnatal wards till discharge. Neonatal data were collected during management of the case. Maternal data were collected from maternal records. Those with gestational diabetes were diagnosed based on International Association of Diabetes and Pregnancy Study Group criteria ${ }^{5}$ and their glucose levels were rechecked in puerperium. All prediabetics were excluded from the study. Those detected before 24 weeks were compared with those detected after 24 weeks.

Statistical analysis was done on excel spreadsheet using XL Miner analysis. All continuous variables were expressed as mean with standard deviation and categorical variables were expressed as percentage and ratios. Comparison between groups for mean and proportion was done with student $t$ test and Chi square test respectively.

\section{Results}

Out of 2554 mothers delivered in the hospital over the year there were 72 mothers who had gestational diabetes $(2.82 \%) .45 .8 \%$ were early gestational diabetes while $54.1 \%$ were late onset gestational diabetes(Table 1). There was pregnancy induced hypertension in
$20.83 \%$ while $12.5 \%$ had hypothyroidism and were on eltroxine.

The mean gestation of early onset GDM was $16.45 \pm 4.74$ weeks compared to $33.08 \pm 4.21$ weeks in late onset. Though the majority were managed with diet modification, $33.33 \%$ received insulin. In the early onset group 18(54.5\%) required insulin compared to 6 $(15.38 \%)$ in the late onset group which was statistically significant $(p<0.05)$ (Table 3$)$.

Of the newborns $17(23.6 \%)$ were preterm. Though $3(4.17 \%)$ were macrosomic $(>4 \mathrm{~kg}), 15(20.83 \%)$ were low birth weight. $40.28 \%$ had neonatal stay more than 24 hours and the overall complication rate was $44.44 \%$. Table 2 shows that hyperbilirubinaemia in $16.67 \%$ followed by hypoglycaemia in $9.72 \%$ was the commonest complication.

Macrosomia and congenital malformation were predominantly seen in early onset gestational diabetes mellitus (Fig 1).

There was higher incidence of complication in early onset $(60.6 \%)$ compared to late onset $(30.77 \%)$ which was statistically significant $(p<0.05)$.Similarly there was statistically significant differences in the duration of NICU stay.

Of the congenital malformation one was dysmorphic with cleft palate and the other had intestinal bands. In the late group, one new-born was diagnosed with Down's syndrome. In the early onset group the respiratory problem was due to hyaline membrane disease while in the late onset group there was transient tachypnoea of new-born. There was no statistically significant difference in the types of complication between the groups.

Table 1: Maternal variables

\begin{tabular}{lc}
\hline Parameters & $\mathbf{n}=\mathbf{7 2}^{*}$ \\
\hline Age $(\mathrm{yrs})$ & $28.92 \pm 4.91$ \\
\hline Age $>35 \mathrm{yrs}$ & $9(12.5)$ \\
\hline $\mathrm{BMl}>30 \mathrm{~kg} / \mathrm{m} 2$ & $13(18.06)$ \\
\hline Gestation at diagnosis & $24.61 \pm 9.14$ \\
\hline Gestation $<24$ wks & $33(45.8)$ \\
\hline Gestation $\geq 24$ wks & $39(54.1)$ \\
\hline Glucose $(\mathrm{mg} / \mathrm{dl})$ & $152.33 \pm 22.29$ \\
\hline HbA1c & $6.55 \pm 0.63$ \\
\hline Insulin & $24(33.3)$ \\
\hline Hypothyroidism & $9(12.5)$ \\
\hline Pregnancy induced hypertension & $15(20.83)$ \\
\hline Asthma & $1(1.39))$ \\
\hline Polyhydramnios & $3(4.17)$ \\
\hline Caesarean & $54(75)$ \\
\hline
\end{tabular}

*Mean \pm SD; (\%) 
Table 2: Neonatal variables. ${ }^{*}$ Mean \pm SD

\begin{tabular}{lc}
\hline Parameters & $\mathbf{n = 7 2 ( \% )}$ \\
\hline Gestation at delivery(wks) & $36.55 \pm 2.27^{*}$ \\
\hline Preterm & $17(23.6)$ \\
\hline Birth weight & $2.63 \pm 0.81$ \\
\hline Weight $>4 \mathrm{~kg}$ & $3(4.17)$ \\
\hline Weight $<2 \mathrm{~kg}$ & $15(20.83)$ \\
\hline OFC(cm) & $32.95 \pm 1.71$ \\
\hline Sex M:F & $1.4: 1$ \\
\hline Glucose level(mg/dl) & \\
\hline 2 hours & $86.33 \pm 11.36$ \\
\hline 6 hours & $89.78 \pm 8.95$ \\
\hline 12 hours & $82 \pm 22.14$ \\
\hline 24 hours & $80.79 \pm 17.27$ \\
\hline NICU admission \& stay $>24 h r s$ & $29(40.28)$ \\
\hline Respiratory distress & $4(5.56)$ \\
\hline Cardiac & $2(2.78)$ \\
\hline Congenital anomalies & $3(4.16)$ \\
\hline Hypoglycaemia & $7(9.72)$ \\
\hline Hyperbilirubinaemia & $12(16.67)$ \\
\hline Sepsis & $1(1.39)$ \\
\hline
\end{tabular}

\section{Discussion}

Gestational diabetes was seen to complicate $2.8 \%$ of pregnancy in our hospital which is in the lower range of prevalence of $1-14 \%$ reported based on different screening method and diagnostic criteria ${ }^{6}$. The association of pregnancy induced hypertension in gestational diabetes and increased incidence of caesarean section that we see in our study has been documented $^{6,7,8}$. Multiple studies ${ }^{6,7,9,10}$ have reported increased premature onset of labour/preterm deliveries which can explains the high incidence of preterm and low birth weight babies. As a result, our mean birth weight of new-borns remained within normal range as seen in the Polish study though other studies have reported large babies ${ }^{2,8,11}$. There is an incidence of $16.6 \%$ hyperbilirubinaemia which is comparable to the Polish study ${ }^{9}$ though much higher than $8 \%$ reported from studies in India ${ }^{10}$ and Saudi ${ }^{6}$ and lower than 23 and $29.3 \%$ in studies from Saudi ${ }^{9}$ and Kolkata ${ }^{7}$ respectively. The incidence of hypoglycaemia in our study falls within the range reported in various studies of $2.7 \%$ to $16 \% \%^{6,7,9,11}$. Though the study ${ }^{3}$ on impact of glycaemic control on neonatal outcome shows that macrosomia

Table 3: Comparison between early and late onset diabetes mellitus. *mean \pm SD

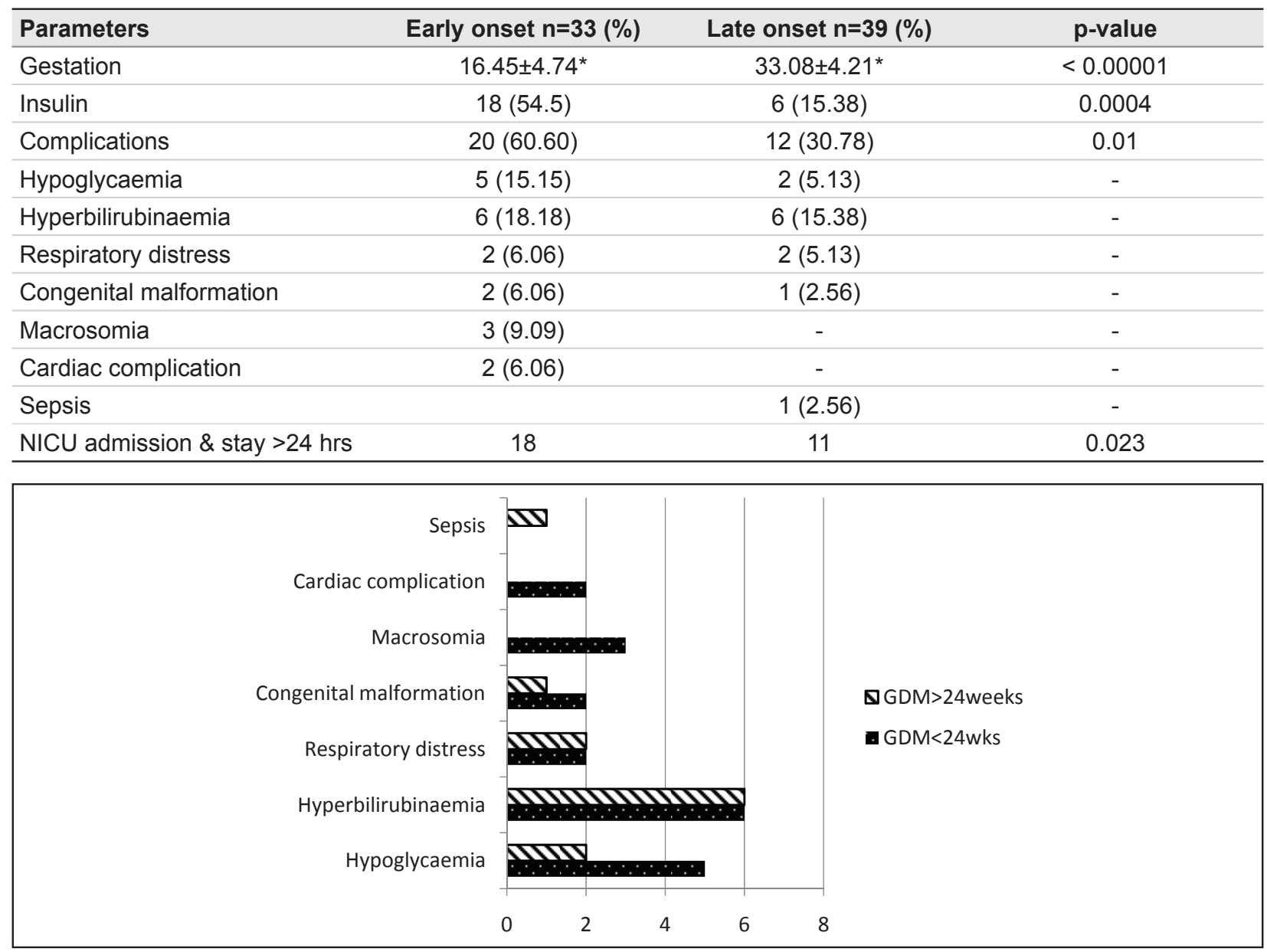

Fig 1: Neonatal Complications of early and late onset Gestational Diabetes 
and still birth have declined with good glycaemic control, study on early onset gestational diabetes continue to show incidence of macrosomia ${ }^{1}$ as we have reported. There is a study from $\mathrm{Uganda}^{2}$ reporting high incidence of macrosomia, still birth and shoulder dystocia. In all such cases we need to look at the control of maternal glycaemia which varies from hospital to hospital. Studies with gestational diabetes detected in early pregnancy are however limited. The higher complications, NICU admission and increase use of insulin seen in early pregnancy in our study is collaborated. Though these studies $^{12,13}$ showed significantly increase incidence of hypoglycaemia in early onset, our study failed to show significant differences in the incidence of hypoglycaemia or hyperbilirubinaemia in the two groups due to small sample size.

\section{Conclusion}

Gestational diabetes is known to cause complications in new-born. With strict maternal glycaemic control the pattern of complications are changing. Screening for hyperglycaemia in mothers early in pregnancy can help to identify high risk neonates for better monitoring and management of complications for paediatrician working in neonatal care.

\section{References}

1. Sweeting AN, Ross GP, Hyett J, Molyneaux L, Constantino M, Harding AJ, Wong J. Gestational Diabetes Mellitus in Early Pregnancy: Evidence for Poor Pregnancy Outcomes Despite Treatment. Diabetes Care 2016;39(1):75-81. doi: 10.2337/dc150433. Epub 2015 Dec 8.

2. Odar E, Wandabwa J, Kiondo P. Maternal and fetal outcome of gestational diabetes mellitus in Mulago Hospital, Uganda.Afr Health Sci 2004;4(1):9-14.

3. González-Quintero VH, Istwan NB, Rhea DJ, Rodriguez LI, Cotter A, Carter J, Mueller A, Stanziano GJ. The impact of glycemic control on neonatal outcome in singleton pregnancies complicated by gestational diabetes.Diabetes Care 2007;30(3):467-70.

4. Jain A, Aggarwal R, JeevaSankar M, Agarwal R, Deorari AK, Paul VK.Hypoglycemia in the Newborn. Indian J Pediatr 2010;77:1137-142.doi: 10.1007/ s12098-010-0175-1

5. Seshiah V, Kalra S, Gupte S, Divakar H, Murugananthan A, Banerjee S, Gupta S, Balaji V, ZargarAH, DasAK, Sahay R, Singh J, Sadikot S, and Khadgawat R. Classification of hyperglycemia in pregnancy. Indian J EndocrinolMetab2014;18(4):445-48. doi:10.4103/2230-8210.137484

6. Gasim T. Gestational diabetes mellitus: maternal and perinatal outcomes in 220 Saudi women. Oman Med J 2012;27(2):140-4.
7. Ghosh S, Ghosh K. Maternal and neonatal outcomes in gestational diabetes mellitus.J Indian Med Assoc 2013;111(5):330-1, 336.

8. Johns K1, Olynik C, Mase R, Kreisman S, Tildesley H. Gestational diabetes mellitus outcome in 394 patients. J ObstetGynaecol Can 2006;28(2):122-7.

9. Malinowska-Polubiec A, Czajkowski K, Sotowska A. Pregnancy and delivery course in patients with gestational diabetes mellitus. Ginekol Pol 2003;74(10):1200-7.

10. Deorari AK, Kabra SK, Paul VK, Singh M. Perinatal outcome of infants born to diabetic mothers. Indian Pediatr 1991;28(11):1271-5.

11. Al-Khalifah R, Al-Subaihin A, Al-Kharfi T, Al-Alaiyan $\mathrm{S}$, Alfaleh KM. Neonatal short-term outcomes of gestational diabetes mellitus in Saudi mothers: a retrospective cohort study.J ClinNeonatol 2012;1(1):2933. doi: $10.4103 / 2249-4847.92241$

12. Bartha $\mathrm{JL}^{1}$, Martinez-Del-Fresno $\mathrm{P}$, Comino-Delgado R. Gestational diabetes mellitus diagnosed during early pregnancy.Am J ObstetGynecol 2000;182(2):346-50.

13. Easmin $\mathrm{S} 1$, Chowdhury TA, Islam MR, Beg A, Jahan MK, Latif T, Dhar S, Alam MN, Akhter. Obstetric Outcome in Early and Late Onset Gestational Diabetes Mellitus.Mymensingh Med J 2015;24(3):450-6. 